\title{
Intracranial Mesenchymal Chondrosarcoma: Case Report and Review of Literature
}

\author{
Kazem Anvari ${ }^{1}$, Masoumeh Gharib ${ }^{2}$, Amin Saburi $^{3}$, Seyed Alireza Javadinia ${ }^{4 凶}$
}

\author{
${ }^{1}$ Cancer Research Center, Faculty of Medicine, Mashhad University of Medical Sciences, Mashhad, Iran \\ ${ }^{2}$ Department of Pathology, Faculty of Medicine, Mashhad University of Medical Sciences, Mashhad, Iran \\ ${ }^{3}$ Birjand Atherosclerosis and Coronary Artery Research Center, Birjand University of Medical Sciences, Birjand, IR Iran \\ ${ }^{4}$ Student Research Committee, Faculty of Medicine, Mashhad University of Medical Sciences, Mashhad, Iran
}

\begin{abstract}
Background: Chondrosarcoma is a very rare brain tumor. Patients with mesenchymal chondrosarcoma have a worse prognosis and survival than other subtypes of brain chondrosarcoma. Case Report: A 29-year-old man underwent craniotomy because of a headache and blurred vision in his left eye lasting for 15 days. Pathologic examination revealed mesenchymal chondrosarcoma. Conclusion: Chondrosarcoma should be considered in the differential diagnoses of intracranial extra-axial hypo- and hypervascular tumors, especially in young patients. Surgical resection and radiotherapy are the preferred treatment for these patients.[GMJ.2016;5(4):21924]
\end{abstract}

Keywords: Central Nervous System Neoplasms; Primary Supratentorial Neoplasms; Mesenchymal Chondrosarcoma; Chondrosarcomas; Mesenchymal

\section{Introduction}

$\mathrm{C}$ hondrosarcoma is a malignant neoplasm that produces a cartilaginous matrix. It is a rare, high-grade malignant tumor that usually originates from soft and bone tissues. Approximately $2 \%$ of chondrosarcomas include mesenchymal subtype, which in some cases occur in extraskeletal places, especially base of the skull [1]. Patients with mesenchymal chondrosarcoma have worse prognosis and survival than other subtypes of brain chondrosarcoma. Mesenchymal chondrosarcoma is divided into well, moderately, and poorly differentiated histologic grades [2]. We describe the clinical, radiological, and pathological features of a non-skull based intracranial extra-axial mesenchymal chondrosarcoma in a 29-year-old man.

\section{GMJ \\ 2016 Galen Medical Journal \\ Tel/Fax: +98 7136474503 \\ PO Box 7193616563 \\ Email:info@gmj.ir}

\section{Case Presentation}

A 29-year-old man with no significant past medical history was referred to a neurosurgeon with a two-week history of a headache and blurry vision in his left eye. He had a headache on left side of the head that became progressively more severe. Patient mention that his headache intensified in the morning and was accompanied by nausea and vomiting. Physical examination consists of an examination of cranial nerves examination, muscle strength, tone and bulk, reflexes, coordination, sensory function and gait showed no significant clinical sign. Visual acuity was measured according to the size of letters viewed on a Snellen chart revealing a low visual acuity in the left eye around 0.6 LogMAR. There was no pathologic finding in the funduscopic evaluation.

\footnotetext{
Correspondence to:

Seyed Alireza Javadinia, MD, Resident of Radiation Oncology, Faculty of Medicine, Mashhad University of Medical Sciences, Mashhad, Iran

Telephone Number: +98 5138426936

Email Adress: javadiniaa941@mums.ac.ir
} 
On magnetic resonance imaging (MRI) (T1, T2-weighted, and flair images), a $45 \mathrm{~mm}$, iso- to hyperintense mass was noted in the left frontoparietal region, which caused edema and disappearance of the anterior horn of the left lateral ventricle accompanied by midline shift. It seemed more likely to be of extra-axial origin, but it could not be exactly determined, radiographically (Figure-1).

The meningeal tail was not found. Radiographic differential diagnoses were meningiomas, hemangiopericytoma, and gliomas.
The patient underwent craniotomy, and the mass (size: $4 \times 3.5 \times 3.5 \mathrm{~cm}$ ) was resected en bloc. However, the surgeon was not able to determine the exact site of tumor origin. The patient tolerated the procedure well, without significant post-operative complications.

Pathologic examination showed a tumor demonstrating two distinct components. There was a densely cellular component comprised of the closely packed oval to spindled cells with hyperchromatic nuclei and scant cytoplasm, which were transected by slit-like

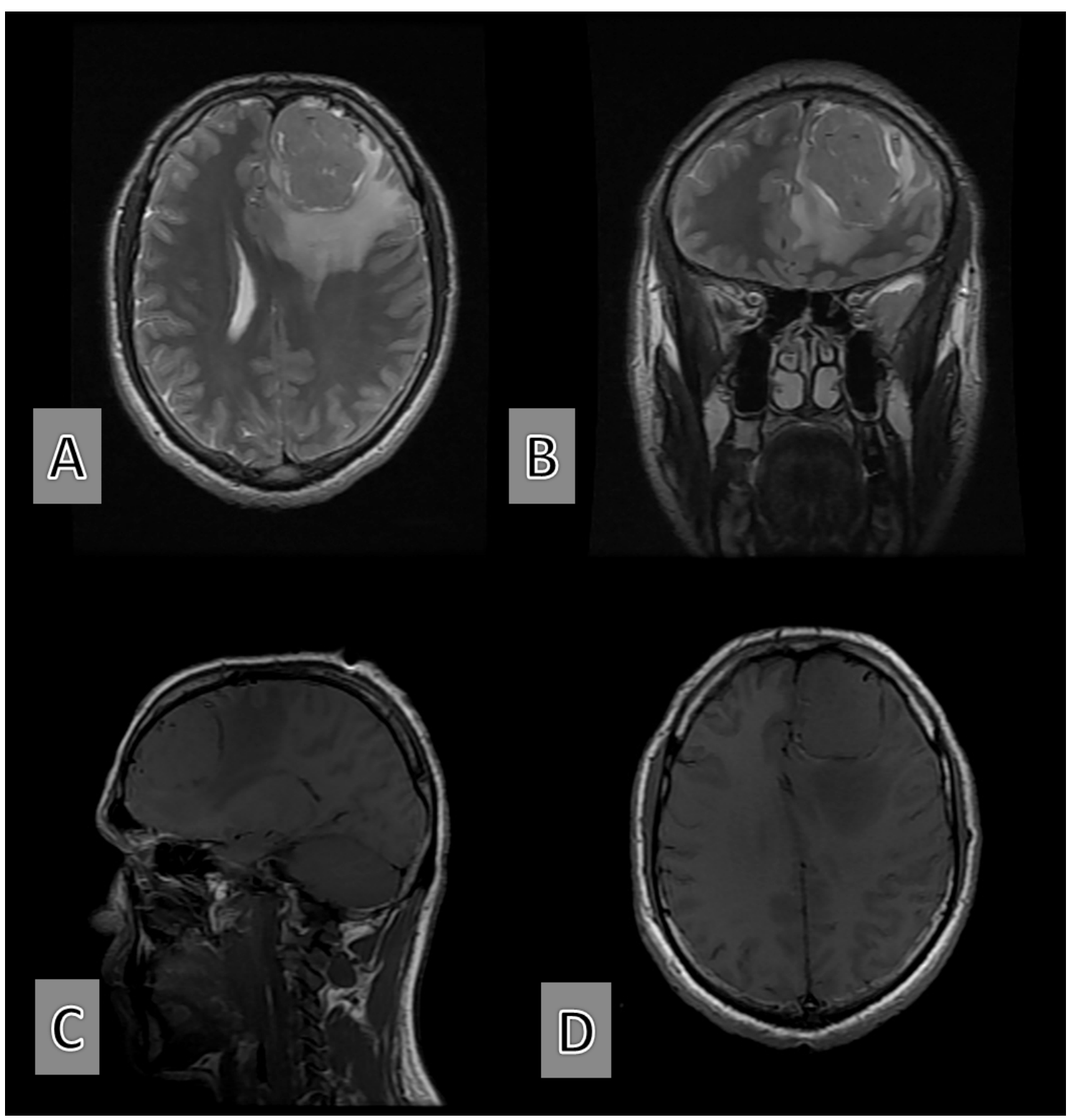

Figure 1. Pre-operative Brain MRI of the patient. The T2 weighting shows an iso- to hyperintense mass in frontoparietal of the brain, with some degree of edema in posterior and inferior of the tumor (A and B). On T1 weighted imagines it is isointense lesion (C, D). 
vessels imparting a hemangiopericytoma-like appearance and punctuated by islands of mature-appearing cartilage. The second opinion of an expert pathology consultant confirmed the diagnosis of mesenchymal chondrosarcoma. This tumor was nonreactive for epithelial membrane antigen (EMA) and did not label for CD34, Ck, GFAP, or smooth muscle actin (SMA). The S100 was positive only in the cartilaginous areas, and CD99 and Bcl-2 were positive in the hemangiopericytoma-like component (Figure-2).

Metastatic workup did not show any evidence of distant metastasis. Postoperative computed tomography scan with intravenous contrast revealed treatment-related tumor bed chang- es, without any evidence of residual mass.

Two months after surgery, he received adjuvant radiotherapy (60 Gy) with a local field (Tumor bed plus $1.5 \mathrm{Cm}$ margin as CTV and Plus $0.5 \mathrm{Cm}$ for PTV), in 30 Fractions by using a three-dimensional conformal technique. The patient was followed radiographically with MRI for one year. There was no evidence of local recurrence.

\section{Discussion}

The first case of intracranial chondrosarcoma was reported in 1899 , and since then numerous reports have been published in this contest. This type of brain tumor is rare and
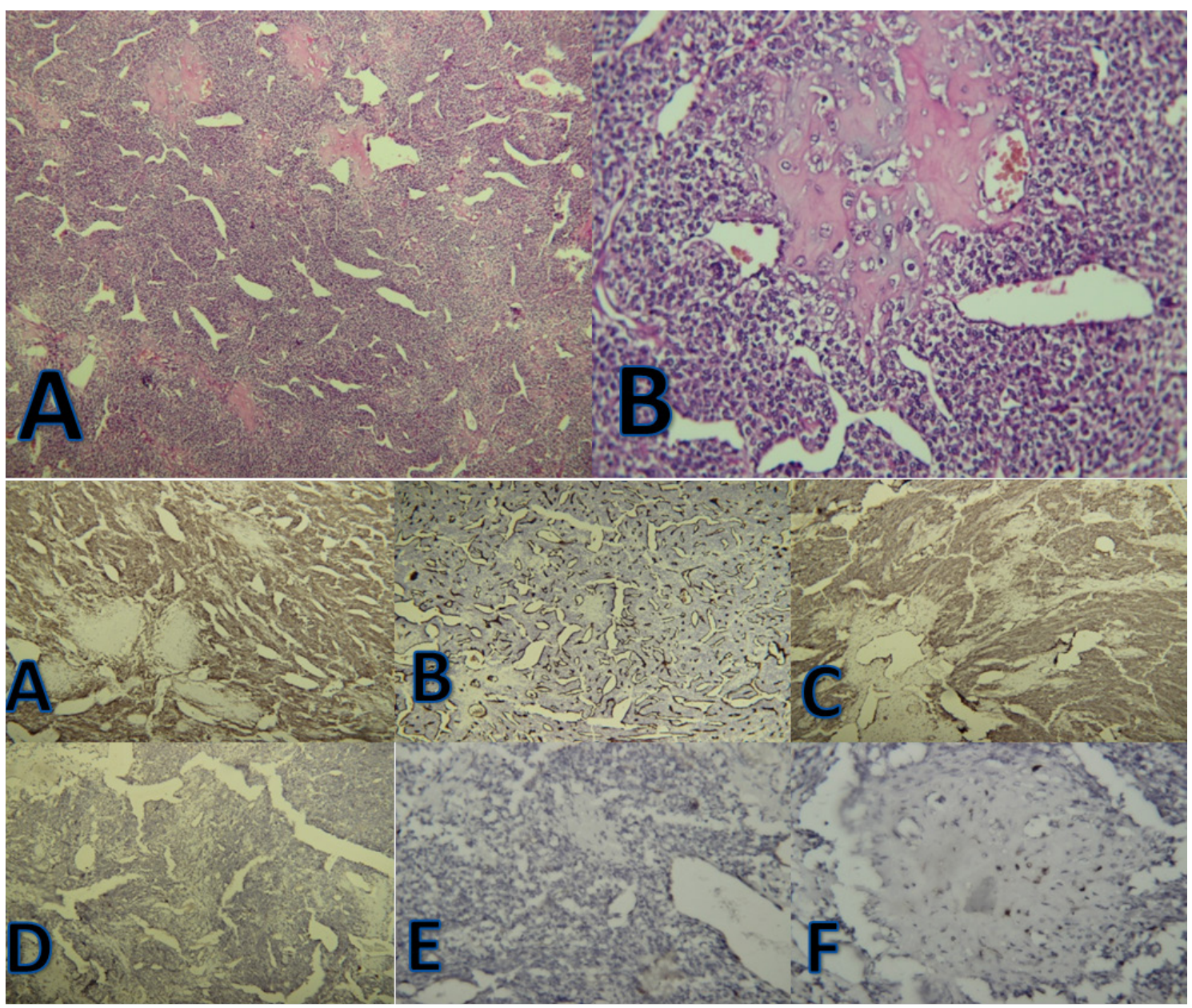

Figure 2. Mesenchymal chondrosarcoma immunohistostaining photomicrographs. A: illustrates a cellular, hemangiopericytoma-like component and chondroid islands (40x); B: shows an island of well-differentiated cartilage in the center (400x); C: undifferentiated area showing cytoplasmic immunostaining for Bcl-2; D: negative immunostaining for CD34; E: immunoreactivity for CD99 in the undifferentiated area; F and G: negative immunostaining for GFAP and EMA; $\mathrm{H}$ : focal S100 positivity in chondroid island 
only forms $0.15 \%$ of all primary intracranial tumors. A mesenchymal subtype of chondrosarcoma, as our presented patient, is extremely uncommon. It is slightly more common in women and the third decade of life [3-5]. Intracranial chondrosarcoma is often present as a single tumor that grows progressively and shows signs of increased intracranial pressure [2].

Table-1 shows a review of some literature about intracranial extraskeletal mesenchymal chondrosarcomas.

Table 1. The Review of Some Literature about Intracranial Extraskeletal Mesenchymal Chondrosarcomas

\begin{tabular}{|c|c|c|c|c|c|}
\hline Authors & $\begin{array}{c}\text { Age of } \\
\text { Patient (s) }\end{array}$ & Symptoms & Location & Imaging Findings & Outcome \\
\hline $\begin{array}{l}\text { Sadashiva et al. } \\
{[10]}\end{array}$ & $\begin{array}{c}52,42 \text { and } \\
7 \mathrm{yr}\end{array}$ & $\begin{array}{l}\text { Comatose stage } \\
\text { and general } \\
\text { symptoms }\end{array}$ & $\begin{array}{l}\text { 2/3 anterior } \\
\text { and mid falx } \\
\text { and dural }\end{array}$ & $\begin{array}{l}\text { Hyperostosis of } \\
\text { bone and Mass }\end{array}$ & Various \\
\hline Yan et al. [3] & $\begin{array}{l}\text { Young } \\
\text { adult }\end{array}$ & & Broca's area & $\begin{array}{l}\text { A mass invade } \\
\text { broca area }\end{array}$ & $\begin{array}{l}\text { Good with } \\
\text { total resection } \\
\text { guided by intra- } \\
\text { operative MRI } \\
\text { combined with } \\
\text { neuronavigation. }\end{array}$ \\
\hline Xiao et al. [4] & $23 \mathrm{yr}$ & $\begin{array}{c}\text { Meningioma like } \\
\text { symptoms }\end{array}$ & $\begin{array}{c}\text { Posterior } \\
\text { cranial fossa }\end{array}$ & $\begin{array}{l}\text { Lobulated soft- } \\
\text { tissue mass with } \\
\text { the dura-attached } \\
\text { base, patchy } \\
\text { calcifications, and } \\
\text { heterogeneous } \\
\text { signal intensities. }\end{array}$ & $\begin{array}{c}2 \text { y optimistic } \\
\text { prognosis }\end{array}$ \\
\hline Khan et al. [6] & $40 \mathrm{yr}$ & $\begin{array}{c}\text { Headache, loss of } \\
\text { vision }\end{array}$ & $\begin{array}{l}\text { Sphenoidal } \\
\text { based }\end{array}$ & $\begin{array}{l}\text { A soft tissue mass } \\
\text { with calcification } \\
\text { simultaneous with } \\
\text { craniopharyngioma }\end{array}$ & \\
\hline Thakar et al. [5] & $35 \mathrm{yr}$ & $\begin{array}{l}\text { Impaired visual } \\
\text { acuity and } \\
\text { complete external } \\
\text { ophthalmoplegia }\end{array}$ & $\begin{array}{l}\text { Anterior } \\
\text { skull base }\end{array}$ & $\begin{array}{l}\text { Enhancing mass } \\
\text { with extensions }\end{array}$ & Lost to follow-up \\
\hline Kan et al. [7] & $31 \mathrm{yr}$ & $\begin{array}{l}\text { Severe headache, } \\
\text { intermittent nausea } \\
\text { and vomiting }\end{array}$ & $\begin{array}{c}\text { Bilateral } \\
\text { frontal and } \\
\text { based on the } \\
\text { anterior falx } \\
\text { cerebri, }\end{array}$ & $\begin{array}{c}\text { Heterogeneous, } \\
\text { intensely enhancing } \\
\text { mass }\end{array}$ & \\
\hline Saito et al. [8] & $31 \mathrm{yr}$ & $\begin{array}{l}\text { Right } \\
\text { homonymous } \\
\text { hemianopsia }\end{array}$ & $\begin{array}{l}\text { Occipital } \\
\text { region }\end{array}$ & $\begin{array}{c}\text { Heterogeneously } \\
\text { enhanced mass with } \\
\text { calcification }\end{array}$ & $\begin{array}{c}\text { Good, } 20 \text { months } \\
\text { f/up }\end{array}$ \\
\hline $\begin{array}{l}\text { Kathiravel et al. } \\
\text { [11] }\end{array}$ & $32 \mathrm{yr}$ & $\begin{array}{l}\text { Long-term } \\
\text { weakness }\end{array}$ & Ant falcine & $\begin{array}{c}\text { Irregular } \\
\text { parasagittal mass }\end{array}$ & \\
\hline $\begin{array}{l}\text { De Cecio et al. } \\
{[12]}\end{array}$ & $2 \mathrm{~m} / \mathrm{o}$ & & Parietal & $\begin{array}{l}\text { Large left parietal } \\
\quad \text { solid mass }\end{array}$ & $\begin{array}{l}\text { Died after one } \\
\text { week }\end{array}$ \\
\hline
\end{tabular}


A long and progressive history of a headache, increased intracranial pressure, oculomotor nerve palsy, and vision impairment has been observed in most patients $[2,6-8]$. The origin of intracranial chondrosarcoma can be from the skull base, meninges or within the brain parenchyma. In this patient, according to surgical observations and radiology reports, the probable origin of chondrosarcoma was the meninges. It seems likely that meningeal chondrosarcoma originates from the metaplasia of meningeal fibroblasts or the proliferation of multipotent mesenchymal progenitor cells. However, the pathogenesis of these tumors is not well understood. Curiously, the mesenchymal chondrosarcoma seems to have a special predilection for the dura among extraosseous sites.

Although chondrosarcoma is avascular and calcified in most of the cases, the MRI of this patient showed a single, round isointense mass with peripheral edema. In some instances, intracranial chondrosarcoma has rich vascular components with a vivid enhancement that make it difficult to differentiate from meningiomas or even craniopharyngioma $[5,6]$. Based on a systematic review, a 5-year mortality rate of $11 \%$ and median survival of 24 months were reported in the patients. Mortality rate was higher in those with high-grade or mesenchymal subtype [2].

Mesenchymal chondrosarcomas of dural origin routinely harbor anaplastic small cell elements in peri stomatous architectural array and should be differentiated from meningeal hemangiopericytoma. However, the latter lacks chondroid components. The extent of cartilaginous differentiation can be highly variable. Obviously, the diagnosis of mesenchymal chondrosarcoma and its distinction from other primitive tumors is most challenging when the cartilaginous component is only focally present or not well represented in a biopsy specimen. Highly vascularized meningiomas are one of the key differential diagnoses; however, these should be immunoreactive for EMA.

However, the immunohistochemical profile of mesenchymal chondrosarcoma is not terribly specific. The tumor cells are not immunoreactive for desmin, cytokeratin, or EMA. The tumor is S100 positive, but only in the cartilaginous areas. The selective use of immunohistochemical stains is helpful in eliminating other tumors that arise in the differential diagnosis. Of note, the small round cell component of mesenchymal chondrosarcoma is consistently immunoreactive for CD99. Thus, mesenchymal chondrosarcoma cannot be distinguished from meningeal hemangiopericytoma by CD99 immunoreactivity alone [1].

Prognosis of these patients is significantly associated with the extent of tumor removal, pathological pattern, and adjuvant radiotherapy [3]. Local recurrence is considered as the most important predictor of mortality [2]. Higher recurrence rate is observed in patients with incomplete resection due to the proximity of the tumor to eloquent organs and vascular structures [9]. Moreover, the recurrence rate is reported to be higher in those patients with mesenchymal chondrosarcoma. In this patient, the tumor was resected en block, followed by adjuvant radiotherapy. However, the preferred treatment of intracranial chondrosarcoma regardless of origin or grade is gross total excision combined with an adjuvant chemotherapy. However, the efficacy chemotherapy in the treatment of intracranial chondrosarcoma is controversial, although there are few reports of their response to temozolomide or ifosfamide-doxorubicin regimens.

\section{Conclusion}

Intracranial mesenchymal chondrosarcoma is a rare malignant tumor, which may cause life-threatening events that affect the quality of life. This tumor should be considered in the differential diagnoses of intracranial, extra-axial hypo- and hypervascular tumors, especially in young people. The important feature of this malignant tumor is slowly growing and with well-defined margins from the adjacent brain parenchyma. Surgical resection and radiotherapy are the treatment of choice for this tumor.

\section{Conflict of Interest}

No conflict of interest 


\section{References}

1. Shakked RJ, Geller DS, Gorlick R, Dorfman HD. Mesenchymal chondrosarcoma: clinicopathologic study of 20 cases. Arch Pathol Lab Med. 2012;136(1):61-75.

2. Bloch OG, Jian BJ, Yang I, Han SJ, Aranda $\mathrm{D}, \mathrm{Ahn} \mathrm{BJ}$, et al. A systematic review of intracranial chondrosarcoma and survival. J Clin Neurosci. 2009;16(12):1547-51.

3. Yan J, Cheng J, Li H, Liu X, Zheng Y, Wang C, et al. Intraoperative high-field magnetic resonance imaging combined with neuronavigation-guided resection of intracranial mesenchymal chondrosarcoma in Broca's area: a rare case report and literature review. Int J Clin Exp Med. 2015;8(3):4697702.

4. Xiao A, Li Z, He X, You C. A rare tentorial mesenchymal chondrosarcoma in posterior cranial fossa: case report. Neurol Neurochir Pol. 2014;48(4):287-91.

5. Thakar S, Dadlani R, Furtado SV, Ghosal N, Hegde AS. Extensive anterior skull-base mesenchymal chondrosarcoma: unusual cause of multiple indolent masses on the forehead. Clin Neuropathol. 2013;32(5):3938.

6. Khan FQ, Mari AR, Afzal R. Sphenoidal intracranial chondrosarcoma. J Coll
Physicians Surg Pak. 2014;24 Suppl 1:S34-6.

7. Kan Z, Li H, Zhang J, You C. Intracranial mesenchymal chondrosarcoma: case report and literature review. Br J Neurosurg. 2012;26(6):912-4.

8. Saito Y, Takemura S, Sakurada K, Sato S, Kayama T. [Intracranial extraskeletal mesenchymal chondrosarcoma arising from falx: a case report and literature review]. No Shinkei Geka. 2010;38(5):441-8.

9. Little A, Chung C, Perez-Ordonez B, Mikulis D, Valiante TA. High-grade intracranial chondrosarcoma presenting with haemorrhage. J Clin Neurosci. 2013;20(10):1457-60.

10. Sadashiva N, Sharma A, Rajalakshmi P, Mahadevan A, Shukla D, Devi BI. Intracranial Extraskeletal Mesenchymal Chondrosarcoma. World Neurosurg. 2016.

11. Kathiravel Y, Finnis ND. Primary falcine chondrosarcoma. J Clin Neurosci. 2008;15(12):1406-9.

12. De Cecio R, Migliaccio I, Falleti J, Del Basso De Caro M, Pettinato G. Congenital intracranial mesenchymal chondrosarcoma: case report and review of the literature in pediatric patients. Pediatr Dev Pathol. 2007;11(4):309-13. 